\title{
Research on the Reform and Development of School Sports Education under the Perspective of Lifetime Sports and Nationwide Fitness
}

\author{
Qiong WANG \\ School OF Physical Education,Zhao Tong Uninversity, \\ Zhaotong,657000,China
}

\begin{abstract}
In this paper, we conduct research on the reform and development of school sports education under the perspective of lifetime sports and nationwide fitness. School physical education is the foundation and the strategic focus of the development of sports which is the foundation of the national fitness program which is also an important part of the whole education career. Our proposed approach and reform combines the advances of the state-ofthe-art methodologies which will not only enhance the current model but set up for prospect and modification as well.
\end{abstract}

Keywords: Sports Education; Lifetime Sports; Nationwide Fitness; Reform and Development.

\section{Introduction}

The emergence and development of lifetime sports, not only for the current school sports system reform, the content and methods have a profound impact and to enrich and improve the quality of the workers life plays a significant role. Therefore, lifetime sports thought is put forward for reform and development of our country school sports play an immeasurable role. Lifetime sports refer to insist on physical exercise and accept physical education for life. It is made up of human development rule and the role of physical exercise and the development of modern society. Lifelong sports emphasize people of different ages to exercise the sustainability of and in the process of life constantly alternates, we can say, this is the lifelong education idea and concept of sustainable development in combination with organic unity of science in physical education, is

\author{
Hai junLIU \\ School OF Physical Education,Zhao Tong Uninversity, \\ Zhaotong,657000,China
}

the modern education, physical education and the perfect combination of modern philosophy and self-conscious infiltration. School physical education is the foundation and the strategic focus of the development of sports, is the foundation of the national fitness program which is also an important part of the whole education career. School sports, lifelong sports and is closely related to the national fitness. But the school physical education emphasizes the students in the school stage study of sports and physical exercise, and lifelong physical education and the national fitness program emphasizes not only children or adolescents in the stage of school physical education and fitness activities, but the life always physical education and fitness activities, and therefore may be of high quality of life, and must adapt the persistent development of individual or society. From the growth of life process can definitely come to the conclusion that: a person as a teenager, physical education and physical health is directly related to the strength of the body for her entire life or career.

College students' sports lifestyle must have the distinct personality characteristics and it is the related construction that must be accomplished by way of personalized sports teaching and practice. Therefore, lifelong sports in colleges and universities should from the teaching goal, teaching mode and teaching evaluation and other aspects to build its practical paradigm. To construct the university sports lifestyle for the teaching goal of personalized sports teaching practice system should be completely beyond the traditional sports teaching idea and pattern. The following separations will account for the idea in detail. (1) 
"Return to life world" as the basic model of the teaching practice. Way of life from life, sports life style can only be formed in the world of sports life. Only "return to life world", the classroom teaching and extracurricular physical exercise "life", and effective organization of the students' sports life in leisure time, in the process, gradually make the student on own initiative will sports as part of the can't or lack of their own life, integrate sports and real life. (2) "Subject" as ties between teachers and students. The main body of teachers and students both sides are equal at any time. Personalized sports teaching as activities between teachers and students, living rooms must be placed in the view of multi-culture. (3) "Inquiry teaching" as the basic model of teacher's teaching. Should be according to the physical education curriculum "physical activity" and "collective exchanges" characteristics, consciously guide the students in class, using the research thinking in each teaching link and inquiry-based learning to understand, to think, to find, experience, interaction, summary, to cultivate students' independent ability of sports life, gradually formed a personalized sports lifestyle. (4) "Incentive and development" as the basic idea of teaching evaluation. Should change the past sole, enclosed type "teacher rating" method, the "student self-evaluation, mutual and teachers", the combination of "form, process and pluralistic evaluation" combination of teaching evaluation method and the content of the teaching evaluation should be mainly examines whether the students form the "sports life style" or "the basis of construction of sports lifestyle". (5) With "independent, autonomous and selforganization" for the students to learn the basic strategy. Personalized sports lifestyle must achieve in each individual students, under the guidance of teachers, independent, autonomous and self-organizing learning strategy is to stimulate the student main body consciousness, exert students' main body role, the only effective way to realize their own learning goals, should be based on the characteristics of sports, in each teaching link to establish cooperative learning group having a common interest in learning, to make every students independent learning in the autonomy, learn from each other in the interaction, on the basis of the personalized development.

In this paper, we conduct research on the reform and development of school sports education under the perspective of lifetime sports and nationwide fitness. Over the past 20 years, the international mass sports and leisure boom began to affect the school sports, school sports in the service for lifetime sports and health leisure activities of new trend. Lifetime sports become the basic direction of school physical education reform. School physical education to the cultivation of people not only focuses on now, look to the future. The detailed research will be introduced in the following parts.

\section{Our Proposed Methodology}

The Traditional School Sports Education. College physical education teaching reform is to develop smoothly which should have a complete guiding ideology. But at present, the reform of college sports teaching guiding ideology has not formed a complete scientific system, which to a large extent restricted the effective development of college PE teaching reform, at the same time to improve the quality of sports teaching in colleges and universities had a negative effect. And, a lot of the reform of college sports teaching thought is mechanically borrowed from other countries or other disciplines, when using, also have no according to own actual situation to deepen, the result is the reform of college physical education guiding ideology is not in conformity with the practice of the reform of university physical education, so that the disconnection between theory and practice before is more serious. Status quo of university's sports teaching reform could be summarized as the follows. (1) Improve the comprehensive quality of college PE teachers. The comprehensive quality of physical education 
teachers and sports teaching quality between the very closely, to a large extent influence the development of colleges and universities sports teaching. In the face of our country the status quo of college PE teachers' comprehensive quality is low, the colleges and universities should try to improve the comprehensive quality of physical education teachers in colleges and universities. Colleges and universities should strengthen the vocational skills training of physical education teachers, through regular training to improve teachers' teaching ability, organization ability and so on comprehensive quality improve, for the improvement of physical education teaching quality lay a good foundation. (2) Sports teaching content and method reform. With the deepening of quality education system, the content of sports teaching in colleges and universities gradually tend to be diversified development, and pay attention to the teaching content to teach sports and fitness methods. (3) Physical education teaching in colleges and universities should be health first, lifelong physical exercise as the guiding ideology of physical education teaching, let the students set up the lifelong sports consciousness, cultivate the habit of physical exercise. Lifelong exercise is comply with the quality of the education system is a kind of brand-new teaching idea, is the development trend of modern physical education teaching in colleges and universities. This guideline pointed out that teachers should increase the awareness of school physical education teaching reform and attention. Physical exercise habit is one of the many habits, and lifetime sports show is the lifelong physical exercise, so the extension of lifelong sports habits is refers to the corresponding class, i.e. automatic behaviors, and connotation refers to the corresponding class attribute, which can be understood as physical exercise for life.

The Lifetime Sports. The meaning of lifetime sports include two aspects: the contents of a refers to the person from beginning to the end of life learning and take part in physical exercise, make sports man in life is always an important and indispensable content. Second, under the guidance of lifetime sports thought, with sports systematic, integrated into a target, is for people in different periods, different life offers me an opportunity for sports activities in the field of practice. Lifetime sports as a kind of culture, how to implement lifelong sports of people through education to the people to become, it is need our thought. Our country is still not enough awareness of lifelong sports and understanding. Therefore, it is necessary to carry out the connotation of lifelong sports and their relations, this paper explores the provide reference to realize the goal of lifelong sports.

Sports is penetration in human social life in a more complex social phenomenon, sports activities is an important part of life in human society, is an important content of personal lifestyle. It is with the continuous development of human history and natural history of the development of the process of suffering. Only the people of both biological attribute and social attribute combination research of lifetime sports thought and behavior process, can fully and accurately grasp the essence of lifelong sports. The national fitness operation mechanism is guides the important guarantee for the sustainable development of the national fitness, for a proper definition of the concept of the national fitness mechanism, is the construction of the national fitness the basis and starting point of the operation mechanism. In the development of the national fitness, the resources of the national fitness development, security, service, assessment and feedback system of the structure, function and its system of internal relations and mutual influence between the system and work process, principle and operation mode of operation laws to the national fitness operation mechanism.

School sports teaching goal whether preschool stage or phase of higher education, the teaching goal to be reached are around cultivate lifelong consciousness of sports, sports fitness and set the current student body and mind development situation. School sports as an 
important part of school education, occupies a certain teaching task, and sports teaching the front-line workers in order to complete the teaching task and teaching activities, ignores the realization of teaching goals. Under the guidance of lifetime sports thought, the school sports, family sports and community sports should reform the teaching idea, the implementation of the "three catch" of school sports education, the primary and secondary schools to grasp sports skills, and pay special attention to the sports special high school and university pays special attention to the professional sports education and literacy, pay attention to skills and hand in hand with the development of sports culture accomplishment, and exerting the function of physical education, especially the sports school sports and family education function, can form a systematization and standardization of sports education model, to ensure the completion of tasks of sports teaching and the realization of teaching goals. Create a good sports culture atmosphere, increase publicity and education of sports culture, and strengthen sports culture's influence on the sports fitness awareness, in order to better promote the development of sports skills and literacy and inheritance; Many inhabitants of fitness crowd should correct understanding of sports fitness value and instill lifelong sports guiding thought, build the culture atmosphere of good health care and rich amateur cultural life fitness crowd.

The Principles of Nationwide Fitness. National fitness policy implementation is the provincial government will national fitness policy into a policy goal and the basic way of it directly determines the realization of the rights of the policy of the national fitness program and the degree and the scope of implementation. There is a strict policy of national fitness and effective execution, carrying out public sports interests can truly into the social public interests of individuals. The implementation of the national fitness policy is based on the relevant interest groups gain and loss considering the process of interest game. "Orderly" refers to the system of the internal composition of the relationship between the various elements or the system the movement state of the relationship between some regularity. Game is a kind of unbalanced game, is not conducive to the overall optimal, the execution of the policy of the national fitness is obviously. As some sports bureau doesn't perform a national fitness policy. The emergence of the national fitness policy execution block is essentially game both sides of the disorder, cause interest imbalance. Only promote the effective implementation of the national fitness policy, promote the national fitness between the subjects of policy execution, execution and executive main body and the target group towards cooperation and competition to make the game both sides form the real Nash equilibrium, toward the orderly game.

The Reform under the Proposed Guidance. School physical education curriculum is an important part of diathesis education, it is shouldering the task of health education training in the new century excellent talents, attaches great importance to the school sports teaching, and comprehensively improve the body quality of talent is a necessary choice to adapt to today's general knowledge economy. Our designed reform could be summarized as the follows. (1) To grasp the essence, activate the research consciousness. "To the teachers as the main research group, to the real problems of teaching as the main research object" are the basic characteristics of school-based teaching and research, but there are a few teachers think that to carry out the school-based teaching and research "is a teaching and research personnel and backbone teachers", has little to do with yourself; Think school-based teaching and research is "listening to lectures, evaluation, organization, teaching view". Aiming at this phenomenon, one is to further increase the intensity of learning, to improve the recognition of school-based teaching and research. The second is typical. Around the research as a 
typical example to teachers, guide the people actively involved in the research of scientific research practice. (2) Increasing investment, improving teaching conditions. At present, there is a shortage of school funding, especially high completed the junior middle school and rural sports funds shortage problem is very outstanding. Implementing school-based teaching and research, for teacher training, not necessary funds guarantee there will be no good effect. (3) Strengthen the leading and enhance the level of research. According to the survey, the teacher asked to strengthen school-based teaching and research activities there are strong professional guide.

\section{Conclusion}

In this paper, we conduct research on the reform and development of school sports education under the perspective of lifetime sports and nationwide fitness. Correct understanding of the role of sports teaching system, is the premise to set up the concept of system. Sports teaching system belongs to the education system, and belongs to the sports system, meanwhile, the structure itself is a have many multi-level system. Therefore, the school sports teaching reform must be from the above two aspects. To improve the quality of the people, especially sports psychological quality, it is a complicated and arduous task. In terms of sports psychological quality, this is to build internal control system, which is the basis for people's initiative. In the future, we will conduct more research to optimize the method.

\section{References}

[1] Huang X L, Jin Y Q, Liang-Qiu L U, et al. Rational Inspections of the Value of School Sports[J]. Journal of Guangzhou Sport University, 2014.

[2] Dong-Hai W U, Deptartment P E, Education $\mathrm{S} \mathrm{O}$, et al. The Realistic Dilemmas and Ways Out of Cultural Mobilization of School Sports[J]. China School Physical Education, 2014.

[3] Zheng B, Tao C W, University H N. Study on Humanism Education Value and Approaches of School Sports Meeting[J]. Journal of Beijing Sport University, 2014.

[4] En-Bo H U, Management S O, University B S. Consideration on the Influential Degree of Corruption on Chinese Football[J]. Journal of Hebei Institute of Physical Education, 